\title{
Effect of co-occurrence of overweight/obesity and psychosocial stress dimensions on risk factors for cardiovascular disease among construction workers
}

\author{
Christopher E. Ekpenyong*, Koofreh Davies
}

Department of Physiology, Faculty of Basic Medical Sciences, University of Uyo, Nigeria

Received: 11 May 2016

Accepted: 04 June 2016

*Correspondence:

Dr. Christopher E. Ekpenyong,

E-mail: chrisvon200@yahoo.com

Copyright: (C) the author(s), publisher and licensee Medip Academy. This is an open-access article distributed under the terms of the Creative Commons Attribution Non-Commercial License, which permits unrestricted non-commercial use, distribution, and reproduction in any medium, provided the original work is properly cited.

\begin{abstract}
Background: Many studies indicate that overweight/obesity and negative psychosocial states are independently associated with increased odds for cardiovascular disease (CVD) risk factors. However, the effect of the cooccurrence of these factors on CVD risk markers has not been adequately investigated, which was the focus of this study.

Methods: The effect of overweight/obesity and psychosocial stress on CVD risk markers was cross-sectionally assessed via questionnaires and on-site physical examination at the construction companies' site clinics and retained hospital. Overweight/obesity was ascertained using anthropometric indices and according to World Health Organization classification. Psychosocial work status was evaluated using a job content questionnaire. The association between overweight/obesity and psychosocial stressors and CVD risk markers was evaluated using multiple regression models when they occurred alone, and adjusted for sociodemographic factors when they cooccurred.

Results: High social demand conferred 1.85, 2.38, 1.72, and 1.05 odds for hypertension, smoking, alcohol intake, and diabetes mellitus, respectively, in normal weight participants and 2.50, 4.01, 2.64, and 2.81 in obese participants. Likewise, low decision latitude and low social support conferred greater odds for CVD risk markers in overweight/obese versus normal weight participants.

Conclusions: Overweight/obesity and psychosocial stressors increased the odds for CVD risk markers when they occurred alone, but conferred greater odds for CVD risk markers when they co-occurred, after controlling for the effect of potential confounders. In addition to psychosocial stressors, interventions at work sites to improve workers' cardiovascular health should include other traditional CVD risk factors, such as overweight/obesity, to achieve complete success.
\end{abstract}

Keywords: Psychosocial, Adiposity, Cardiac risk, Work environment, Workers

\section{INTRODUCTION}

Worldwide, there is a continuous upgrading of institutional and organizational aspects of the construction industry in response to globalization of the economy, technological advancements, and changing consumer preferences. ${ }^{1}$ In line with the global transformation drive in the public and private sectors, the demand for proficiency and high productivity from the building construction sector is ever increasing. In order to thrive in this competitive environment, various construction companies continuously upgrade the building process; alter the working environment and nature of the work, work force, work pace, and complexity of work; and upgrade machinery, leaving each construction worker to battle daily with mental, physical, and psychosocial stress. Psychosocial stress encompasses many dimensions, including psychological 
demands, decision latitude, and social support. There is also an increased expectation for self-actualization, reliance on interpersonal coordination in the execution of work tasks, and increasing job insecurity. ${ }^{2,3}$

Research has traced psychosocial stress to physical conditions, organizational structure, interpersonal conflict, nature of work, and personal characteristics, including overweight and obesity. ${ }^{4}$ There is increasing evidence that psychosocial stress may contribute to overweight/obesity, particularly abdominal or central obesity, through chronic activation of the neuroendocrine system. $^{2}$

In particular, the risk of obesity may increase in highdemand, low-control work environments and for lateshift work, night duty, and those who work long hours. ${ }^{5,6}$ In addition, high social support at work has been shown to be associated with overweight. ${ }^{7}$ Perceived social support protected against central obesity and the risk of coronary heart disease, whereas lack of emotional support caused excessive eating and drinking and led to obesity. ${ }^{8}$

Conversely, obesity has been shown to adversely affect the psychosocial and psychological well-being of workers. 9 Obesity and psychosocial work factors are associated with several health effects, including risk factors for cardiovascular disease (CVD). ${ }^{10}$ Many studies have shown that psychosocial factors related to work environment increase the risk of incident CVD and affect progress in cardiac patients. ${ }^{11}$ A collaborative study by Tsutsuni et $\mathrm{al}^{12}$ recorded a positive association between job strain and low vegetable/high alcohol consumption.

Conversely, Lallukka et al found that mentally strenuous work and high job control were associated with good dietary habits. ${ }^{13}$

Some evidence suggests direct and indirect effects of psychosocial stress in the aetiology of CVD risk factors. Direct mechanisms may be related to stress-induced alteration in the hypothalamic pituitary adrenal axis, autoimmune dysfunction, inflammation, and induction of prothrombotic state. These are known to affect various physiological and biochemical endpoints, such as increased blood pressure, dyslipidaemia, hyperglycaemia, high glycated haemoglobin concentration, and high plasma fibrinogen concentration. ${ }^{14-17}$

Indirect pathways may be initiated via genetic predisposition, low adherence to health recommendations, and poor lifestyle choices/behavioural risk factors, such as poor eating behaviours, poor physical activity status, excessive alcohol consumption, smoking, and other behaviours that may lead to overweight and obesity. ${ }^{13,15}$ One study showed that stress alters food choices in humans and causes a shift toward energydense foods that contain saturated fats and simple sugars. ${ }^{18}$ Many studies evaluated the relationships between psychosocial work factors and CVD risk markers and overweight and obesity have been reported as risk factors for CVD in several epidemiological studies. $^{7,10}$ Similarly, many authors have considered multiple aspects of either overweight/obesity or psychosocial work stress in relationship to CVD risk markers. ${ }^{19}$ However, none have simultaneously considered both overweight/obesity and negative psychosocial state.

Relatively little is known about whether the combined risk of obesity and psychosocial stress dimensions and the risk for CVD are addictive, synergistic, or antagonistic when they co-occur. Accurate assessment of the effect of the psychosocial work environment on CVD risk factors in overweight/obese construction workers has often been ignored. Psychosocial work factors and obesity influence each other, while sharing a broad range of biological, socioeconomic, and cultural determinants.

Quantifying the combined effects of obesity and psychosocial stress on CVD risk factors among construction workers is essential in terms of target intervention to reduce their individual and shared CVD risk burden. Previous studies have shown that CVD intervention protocols that focus on multiple risk factors achieve higher success than single-factor intervention strategies. $^{20}$

The aim of this study was to accurately evaluate the effects of the co-occurrence of overweight/obesity and various psychosocial work dimensions on CVD risk factors among construction workers in Nigeria.

\section{METHODS}

This was a cross-sectional study of 265 workers from 2 construction companies in Uyo Metropolis, Southern Nigeria. This number represented $68.8 \%$ of the initial 385 workers who agreed to participate. Others (31.2\%) were excluded for not meeting the inclusion criteria.

The exclusion criteria were inappropriate age $(<18$ and $>65$ years), inappropriate completion of the questionnaire, all workers on full-time sick leave, and work tenure $<1$ year. Those who met the inclusion criteria were voluntarily recruited after signing a written informed consent to participate.

However, before the study commenced, a pre-survey lecture was delivered by the research coordinator to inform the intended participants of the significance/purpose of the study. The study protocol was approved by the Institutional Ethics Committee, and management staff of the construction companies granted approval for the study to be conducted.

\section{Instruments of survey/assessment measures}

Three survey instruments were used in this study, including a self-administrated semi -structured 
questionnaire, anthropometric measures, and a CVD risk factor evaluation. The questionnaire was adapted from previous studies on work strain and CVD. ${ }^{21}$ It covered areas relating to the participants' sociodemographic variables, such as age, sex, marital status, ethnicity, smoking status, and alcohol consumption status. Others included dietary habits, physical activity status, and socioeconomic status (SES). The second part of the questionnaire contained 13 items concerning psychosocial work factors that were selected from the job content questionnaire and other sources. ${ }^{7,22}$

\section{Questions relating to psychosocial work factors}

Questions concerning decision latitude

My job

- Permits freedom of decision, acquisition, and application of new skills

- Is free from conflicting ideas from others

- Has tasks that are often interrupted before they can be completed

- Is characterised by repeated laying off and recruitment of workers

\section{Questions concerning psychosocial job demands}

My job requires

- Working very fast

- Working very hard

- Intense concentration

- Enough time to get the work done

\section{Questions concerning social support}

- How often do you converse freely with your coworkers during break?

- Can you converse with your co-workers while working?

- Does your work require you to have a lot of contact with your co-workers?

- When did you last meet your co-workers outside of the workplace?

- How often do you meet your co-workers at home?

Decision latitude was assessed on a 4-point Likert scale. Each psychosocial assessment index was scored (e.g. psychosocial demand [4 items], decision latitude [4 items], and social support [5 items]) as low (1-2) or high (3-4) for psychosocial demands and decision latitude and as low (1-3) or high (4-5) for social support.

The CVD risk factors evaluated were hypertension (systolic blood pressure [SBP] and diastolic blood pressure $[\mathrm{DBP}])$, diabetes mellitus (DM), hyperlipidaemia (dyslipidaemia), smoking status, overweight/obesity, and alcohol consumption status.
They were measured using standard procedures and during basic clinical examination in the construction companies' site clinics and retained hospital. Hypertension was defined according to the European Society of Hypertension. Normotension was considered as SBP $<140 \mathrm{~mm} \mathrm{Hg}$ and DBP $<90 \mathrm{~mm} \mathrm{Hg}$. Values above these were considered to be in the hypertensive range, as was any individual taking antihypertensive medication. ${ }^{23}$

Diabetes mellitus was diagnosed based on the 2011 revised criteria by the expert committee on the diagnosis and classification of diabetes mellitus. According to these criteria, DM is diagnosed when 2 fasting plasma glucose levels are $\geq 126 \mathrm{mg} / \mathrm{dL} \quad(7.0 \mathrm{mmol} / \mathrm{L})$, two 2-hour postprandial glucose levels are $\geq 200 \mathrm{mg} / \mathrm{dL} \quad(11.1$ $\mathrm{mmol} / \mathrm{L})$ after a glucose load of $75 \mathrm{~g}$, two casual glucose readings are $\geq 200 \mathrm{mg} / \mathrm{dL}(11.1 \mathrm{mmol} / \mathrm{L})$, glycated haemoglobin is $>6.5 \%$, or an individual is taking antidiabetic medication.

The anthropometric variables measured were weight in kilograms (kg) and height in meters $(\mathrm{m})$ using standard procedures. Body mass index (BMI) was calculated as weight $(\mathrm{kg}) /$ height $\left(\mathrm{m}^{2}\right)$. Normal weight was defined as BMI of $18.5-24.9 \mathrm{~kg} / \mathrm{m}^{2}$, overweight $25.0-29.9 \mathrm{~kg} / \mathrm{m}^{2}$, and obesity $\geq 30.0 \mathrm{~kg} / \mathrm{m}^{2}$.

Smoking status was assessed by asking the participants whether they had formerly smoked, were currently smoking, or had never smoked. Those who said they currently smoked on the day of the study were defined as current smokers and those who had not smoked for at least 3 months were classified as ex-smokers, otherwise they were classified as never having smoked.

Drinkers were classified into 3 categories: current drinkers, ex-drinkers, and non-drinkers. Based on dietary habits, participants were grouped into 2 groups: good and poor. Dyslipidaemia was defined as the presence of any of the following fasting serum lipid abnormalities: lowdensity lipoprotein cholesterol $\geq 140 \mathrm{mg} / \mathrm{dL}$, high-density lipoprotein cholesterol $<40 \mathrm{mg} / \mathrm{dL}$, or serum triglyceride $\geq 150 \mathrm{mg} / \mathrm{dL}^{24}$

\section{Assessment of SES of participants}

The SES of workers was assessed using a modified Kuppuswamy's SES assessment scale. ${ }^{25}$ This scale has been found to have a high internal consistency and reliability. It is accepted and has been used previously in related surveys. ${ }^{26}$ Based on the total scores, participants were classified into 3 socioeconomic strata: upper (2629), middle (11-25), and lower (3-10), as described by Ekpenyong and Etukumana. ${ }^{26}$

\section{Statistical analysis}

The sociodemographic characteristics of study participants were analysed using frequency and simple 
percentages. In addition, univariate association between sociodemographic variables of the participants and their obesity status were evaluated using the chi-square test. The distribution of CVD risk factors among obese and non-obese participants was also analysed, and the significance of the association assessed using the chisquare test. Furthermore, the multivariate analysis was performed using multiple logistic regression models with and without adjustment for other covariates.

Hence, odd ratios (ORs) and the corresponding confidence intervals (CIs) were estimated. Statistical analysis was performed using Statistical Product and Service Solutions software (SPSS, version 20.0, IBM
Corp., New York, NY), and statistical significance was established at $\mathrm{p} \leq 0.05$.

\section{RESULTS}

This study comprised 265 participants: 130 (49.1\%) obese and 135 (50.9\%) non-obese. Most of the respondents $(63.8 \%$ obese; $60.8 \%$ non-obese) were between the ages of 18 and 40 years, were married $(60 \%$ obese; $76.2 \%$ non-obese), were of middle SES (48.3\%), were physically active $(50.9 \%)$, did not drink alcohol $(47.9 \%)$, were ex-smokers $(37 \%)$, and had poor dietary habits $(62.6 \%)$.

Table 1: Sociodemographic characteristics of study participants.

\begin{tabular}{|c|c|c|c|c|}
\hline Socio-demographic variables & Total & Overweight/obese (n=130) & Non-obese $(\mathrm{n}=135)$ & P-value \\
\hline \multicolumn{5}{|l|}{ Age } \\
\hline $18-40$ & $162(61.1)$ & $83(63.8)$ & $79(60.8)$ & \multirow{2}{*}{0.445} \\
\hline $41-65$ & $103(38.9)$ & $47(36.2)$ & $56(43.1)$ & \\
\hline \multicolumn{5}{|l|}{ Marital status } \\
\hline Single & $76(28.7)$ & $45(34.6)$ & $31(23.8)$ & \multirow{3}{*}{0.070} \\
\hline Married & $177(16.8)$ & $78(60.0)$ & $99(76.2)$ & \\
\hline Divorce & $12(4.5)$ & $07(5.4)$ & $05(3.8)$ & \\
\hline \multicolumn{5}{|l|}{ Socio-economic status } \\
\hline Upper & $62(23.4)$ & $41(31.5)$ & $21(15.6)$ & \multirow{3}{*}{$0.004 * *$} \\
\hline Middle & $128(48.3)$ & $52(40.0)$ & $76(56.3)$ & \\
\hline Lower & $75(28.3)$ & $37(28.5)$ & $38(28.1)$ & \\
\hline \multicolumn{5}{|l|}{ Physical activity status } \\
\hline Active & $135(509)$ & $56(43.1)$ & $79(58.5)$ & \multirow{2}{*}{$0.012 *$} \\
\hline Inactive & $130(49.1)$ & $74(56.9)$ & $56(41.5)$ & \\
\hline \multicolumn{5}{|l|}{ Dietary habit } \\
\hline Good & $99(37.4)$ & $34(26.2)$ & $65(48.1)$ & \multirow{2}{*}{$<0.001 * *$} \\
\hline Poor & $166(62.6)$ & $96(73.8)$ & $70(51.9)$ & \\
\hline \multicolumn{5}{|l|}{ Alcohol intake } \\
\hline Current drinkers & $63(23.8)$ & $39(30.0)$ & $24(17.8)$ & \multirow{3}{*}{$<0.001 * *$} \\
\hline Ex-drinkers & $75(28.3)$ & $22(16.9)$ & $53(39.3)$ & \\
\hline Non-drinkers & $127(47.9)$ & $69(53.1)$ & $58(43.0)$ & \\
\hline \multicolumn{5}{|l|}{ Smoking } \\
\hline Current smokers & $80(30.2)$ & $37(28.5)$ & $43(31.9)$ & \multirow{3}{*}{0.73} \\
\hline Ex-smokers & $98(37.0)$ & $51(39.2)$ & $47(34.8)$ & \\
\hline Non-smokers & $87(32.8)$ & $42(32.3)$ & $45(33.3)$ & \\
\hline
\end{tabular}

Table 2: Distribution of CVD risk factors according to psychosocial work dimensions and overweight/obesity status.

\begin{tabular}{|c|c|c|c|c|c|c|}
\hline \multirow{2}{*}{$\begin{array}{l}\text { Cardiovascular risk } \\
\text { factors }\end{array}$} & \multicolumn{3}{|c|}{ Overweight/Obese $(n=130)$} & \multicolumn{3}{|c|}{ Normal weight (n=135) } \\
\hline & $\begin{array}{l}\text { Demands } \\
\text { low/high }\end{array}$ & $\begin{array}{l}\text { Decision latitude } \\
\text { low/high }\end{array}$ & $\begin{array}{l}\text { Social support } \\
\text { low/high }\end{array}$ & $\begin{array}{l}\text { Demands } \\
\text { low/high }\end{array}$ & $\begin{array}{l}\text { Latitude } \\
\text { low/high }\end{array}$ & $\begin{array}{l}\text { Support } \\
\text { low/high }\end{array}$ \\
\hline Hypertension & $3(2.3)$ & $9(6.9)$ & $8(6.7)$ & $5(3.7)$ & $3(2.2)$ & $4(3.0)$ \\
\hline Diabetes & $3(2.3)$ & $4(3.1)$ & $7(5.4)$ & $7(5.2)$ & $2(2.2)$ & $5(3.7)$ \\
\hline Smoking & $2(1.5)$ & $6(4.6)$ & $4(3.1)$ & $5(3.7)$ & $9(6.7)$ & $7(5.2)$ \\
\hline Alcohol consumption & $8(6.2)$ & $5(3.8)$ & $15(11.5)$ & $2(1.5)$ & $3(2.2)$ & $1(0.7)$ \\
\hline Low HDL-C & $9(6.9)$ & $4(3.1)$ & $5(3.8)$ & $4(3.0)$ & $7(5.2)$ & $3(2.2)$ \\
\hline
\end{tabular}


A significant association was found between SES, physical activity, dietary habits, and alcohol intake and obesity ( $\mathrm{p}<0.05)$ (Table 1). Table 2 shows the distribution of CVD risk factors according to psychosocial work dimensions. The prevalence of hypertension was higher among obese participants with low decision latitude (6.9\%), while diabetes, smoking, and alcohol consumption were higher in obese participants with low social support, non-obese participants with low decision latitude, and obese participants with low support, as well as obese participants with low psychological demand.

Table 3: Odd ratios ( $95 \%$ confidence intervals Cls) for the effect of co-occurrence of overweight/obesity and psychosocial stress on CVD risk factors.

\begin{tabular}{|c|c|c|c|c|c|}
\hline $\begin{array}{l}\text { Psychosocial } \\
\text { stress } \\
\text { dimensions }\end{array}$ & $\begin{array}{l}\text { Hypertension } \\
\text { OR (95\% C.I) }\end{array}$ & $\begin{array}{l}\text { Low-HDL-C } \\
\text { OR (95\% C.I) }\end{array}$ & $\begin{array}{l}\text { Smoking } \\
\text { OR (95\% C.I) }\end{array}$ & $\begin{array}{l}\text { Alcohol intake } \\
\text { OR ( } 95 \% \text { C.I) }\end{array}$ & $\begin{array}{l}\text { Diabetes } \\
\text { OR (95\% C.I) }\end{array}$ \\
\hline \multicolumn{6}{|c|}{ Psychological demand } \\
\hline Low (non-obese) & 1.00 & 1.00 & 1.00 & 1.00 & 1.00 \\
\hline Low (obese) & $1.52(1.142-3.012)$ & $1.02(0.922-4.714)$ & $2.64(1.988-5.204)$ & $1.53(1.430-3.857)$ & $2.61(2.517-8.664)$ \\
\hline $\begin{array}{l}\text { High (non- } \\
\text { obese) }\end{array}$ & $1.85(1.127-6.312)$ & $1.08(0.998-3.704)$ & $2.38(1.208-4.992)$ & $1.72(1.615-4.330)$ & $1.05(0.759-8.220)$ \\
\hline High (obese) & $2.50(2.422-10.815$ & $1.31(0.822-8.452)$ & $4.01(3.889-15.270)$ & $2.64(2.317-8.457)$ & $2.81(2.792-10.675$ \\
\hline \multicolumn{6}{|l|}{ Decision latitude } \\
\hline $\begin{array}{l}\text { High (non- } \\
\text { obese) }\end{array}$ & 1.00 & 1.00 & 1.00 & 1.00 & 1.00 \\
\hline High (obese) & $1.80(1.312-10.217)$ & $1.22(0.682-1.847)$ & $1.07(0.832-4.018)$ & $0.94(0.412-1.622)$ & $2.64(2.593-8407)$ \\
\hline Low (non-obese) & $1.56(1.121-5.613)$ & $1.09(0.755-2.614)$ & $1.09(0.347-3.087)$ & $0.98(0.536-1.701)$ & $1.05(0.833-7.853)$ \\
\hline Low (obese) & $1.98(1.137-7.246)$ & $1.29(0.974-6.7201)$ & $2.01(1.875-4.033)$ & $1.07(0.987-3.062)$ & 3.47 (2.634-9.850) \\
\hline \multicolumn{6}{|l|}{ Social support } \\
\hline High (non-obese) & 1.00 & 1.00 & 1.00 & 1.00 & 1.00 \\
\hline High (obese) & $1.27(0.124-3.715)$ & $1.02(0.488-3.1422)$ & $2.08(1.982-6.844)$ & $1.72(1.689-7.082)$ & $3.01(2.883-9.857)$ \\
\hline Low (non-obese) & $1.03(0.3216-5.221)$ & $1.09(0.512-4.361)$ & $2.37(1.996-7.518)$ & $1.57(1.466-5.095)$ & $0.97(0.514-1.853)$ \\
\hline Low (obese) & $2.62(1.819-12.622)$ & $1.42(0.871-5.317)$ & $3.22(2.962-10.5021)$ & $2.88(2.614-10.847)$ & $4.22(3.851-16-853$ \\
\hline
\end{tabular}

Table 4: Adjusted odd ratios (95\% confidence intervals Cls) for the effect of co-occurrence of overweight/obesity $(B M I \geq 25 \mathrm{~kg} / \mathrm{m} 2)$ and psychosocial stress on risk factors for CVD.

\begin{tabular}{|c|c|c|c|c|c|}
\hline $\begin{array}{l}\text { Psychosocial Stress } \\
\text { Dimensions }\end{array}$ & $\begin{array}{l}\text { Hypertension } \\
\text { OR (95\% C.I) }\end{array}$ & $\begin{array}{l}\text { Low-HDL-C } \\
\text { OR (95\% C.I) }\end{array}$ & $\begin{array}{l}\text { Smoking } \\
\text { OR (95\% C.I) }\end{array}$ & $\begin{array}{l}\text { Alcohol intake } \\
\text { OR (95\% C.I) }\end{array}$ & $\begin{array}{l}\text { Diabetes } \\
\text { OR (95\% C.I) }\end{array}$ \\
\hline \multicolumn{6}{|c|}{ Psychological demand } \\
\hline Low & 1.00 & 1.00 & 1.00 & 1.00 & 1.00 \\
\hline High & $1.82(1.321-3.015)$ & $1.44(0.654-3.173)$ & $4.25(1.774-29.625)$ & $3.34(2.941-7.921)$ & $2.57(1.654-8.172)$ \\
\hline \multicolumn{6}{|l|}{ Decision latitude } \\
\hline Low & $3.05(1.625-8.271)$ & $0.95(0.825-1.172)$ & $2.47(2.31-8.22)$ & $1.05(0.982-2.447)$ & $1.82(1.721-5.172)$ \\
\hline High & 1.00 & 1.00 & 1.00 & 1.00 & 1.00 \\
\hline \multicolumn{6}{|l|}{ Social support } \\
\hline High & 1.00 & 1.00 & 1.00 & 1.00 & 1.00 \\
\hline Low & $3.42(2.21-40.22)$ & $1.21(0.988-1.824)$ & $3.52(1.871-10.584)$ & $2.87(1.982-10.824)$ & $2.31(2.05-11.072)$ \\
\hline
\end{tabular}

Adjusted for socio-demographics of the respondents

Table 3 shows that the co-occurrence of high social demand and obesity was associated with an OR of 2.50 for hypertension (95\% CI 2.422-10.815), whereas the synergistic effect of low psychological demands and obesity and high psychosocial demands and non-obesity were associated with an OR of 1.52 (95\% CI 1.1423.012 ) and an OR of 1.85 for hypertension (95\% CI 1.127-6.312). In addition, higher risk for developing hypertension was found in obese participants with low decision latitude and low social support dimensions compared with participants in other groups. The effects of psychosocial stress dimensions on the odds for dyslipidaemia were not significantly different between obese and non-obese participants, whereas the odds for alcohol consumption, smoking, and DM were higher among obese participants with high psychosocial 
demands, low decision latitude, and low social support versus non-obese participants. After adjusting for sociodemographic factors, high psychological demand $(\mathrm{OR}=1.82,95 \%$ CI 1.321-3.015), low decision latitude $(\mathrm{OR}=3.05,95 \%$ CI 1.625-8.271), and low social support were still found to be significantly associated with higher odds for CVD risk factors in obese versus non-obese participants.

\section{DISCUSSION}

In this cross-sectional study of male construction workers, the association between psychosocial stress dimensions and CVD risk markers was modified by overweight/obesity. Psychosocial stress and overweight/obesity increased the risk for CVD markers when they occurred alone, and even greater risk when they co-occurred. Accordingly, we found increased risk for CVD markers in obese participants with low psychological demands and in non-obese participants with high psychological demands, indicating their independent CVD risk potential.

However, co-occurrence of these factors (high demands and obesity) conferred greater odds for CVD risk markers among participants. Furthermore, high decision latitude in obese and low decision latitude in normal weight participants were associated with increased odds for CVD risk markers, but greater odds in obese participants with low decision latitude. Likewise, low social support conferred a greater risk in obese versus non-obese participants.

However, in some normal weight participants, the odds for CVD risk markers were either decreased or showed a non-significant increase despite exposure to multiple psychosocial stressors. This observation corroborates findings of previous studies that showed that in some individuals, weight status can modify the effect of psychosocial work stress on incident CVD risk markers. ${ }^{27}$

In addition, a higher frequency of CVD markers was found in overweight/obese versus normal weight participants exposed to various psychosocial stress components, except for decision latitude, which was associated with a higher incidence of smoking in normal weight versus obese participants. This result is consistent with previous studies that showed that exposure to multiple psychosocial risk factors conferred a greater CVD risk than a single-factor effect. ${ }^{28}$

It further supports the theory that a multiple psychosocial disadvantaged state is harmful to health. ${ }^{29}$ On this premise, we hypothesised that the increased risk for CVD markers in normal weight participants observed in this study may in part be due to the effect of single or multiple psychosocial stress dimensions. However, this effect is known to confer a greater risk on overweight/obese versus normal weight individuals.
This proposition has received full support from prior studies that showed that total CVD risk of an individual corresponds to the additive effect of the sum of psychosocial stressors and traditional CVD risk factors. ${ }^{30}$ The more psychosocial stress components an individual is exposed to, the greater the CVD risk, especially in obese individuals. $^{31}$ Existing data suggest a complex bidirectional causal chain between psychosocial stress measures, obesity, and CVD risk markers, otherwise described as the stress-obese-CVD risk factors triangle.

Several psychosocial risk factors have been associated with the development of obesity, and subsequently to metabolic aberrations leading to clusters of CVD risk factors. ${ }^{4,10,32}$ In a French cohort study, Niedhammer et al found a significant association between psychosocial work variables and hypertension, hyperlipidaemia, overweight, smoking, and alcohol intake, but not DM. ${ }^{7}$

It was further observed that the effect of psychosocial stress on CVD risk factors was more pronounced in obese versus normal weight individuals. They observed the protective effect of low social supports on DM in normal weight participants, similar to the observation by Smith et al in their study of Canadian men and women. ${ }^{33}$ Low decision latitude was also protective against alcohol consumption in normal weight participants in this study.

Further supporting the beneficial effect of healthy weight on psychosocial stress-induced CVD risk factors, Heraclide et al found that a higher mean BMI was among the risk factors for the onset of DM among the psychosocially disadvantaged study population. ${ }^{34}$ Smith et al also identified the protective effect of low social support against DM on psychosocially disadvantaged women. ${ }^{33}$

Conversely, overweight/obesity has been found to confer greater odds for the development of the previously mentioned risk factors. ${ }^{35,36}$ Co-occurrence of psychosocial stress and overweight/obesity has indeed conferred greater odds for CVD risk factors as observed in this study. Accordingly, as the constellation of risk factors increases, so does the risk of disease. This finding underlines the recent increased calls to move beyond a single risk factor approach and focus on the co-existence of risk factors. ${ }^{37}$

Previous studies have shown that CVD risk intervention protocols that focus on multiple risk factors achieve higher success than single-factor intervention strategies. ${ }^{20}$ Furthermore, we found a higher incidence of poor dietary habits and alcohol consumption among obese versus normal weight individuals, likely indicating a greater effect of psychosocial stress on obese versus normal weight individuals.

Previous studies have shown that psychosocial stress is associated with poor dietary habits and consumption of alcohol. One study showed that lack of emotional support 
caused excessive eating and drinking, leading to obesity. ${ }^{8}$ Effort-reward imbalance has been found to be associated with smoking, alcohol consumption or dependence, and high BMI. ${ }^{38-40}$

The strength of our study relied on the fact that the variables assessed, including adiposity indices and CVD risk factors, were actually measured and not based on self-reports. In our regression analysis we controlled for most of the potential confounders for CVD risk markers, including age, education status, physical activity status, and dietary habits. This reduced the confounding effect of these factors on the relationship between psychosocial work variables and CVD risk factors.

This study has a number of limitations that merit discussion. For instance, the scale of social support at work was limited to evaluating the frequency of contact with co-workers, but not the satisfaction with the support received, nor the support from supervisors. Also, a crosssectional study may not give a very high degree of evidence to the causal relationship between cooccurrence of overweight/obesity and psychosocial stress of the CVD risk markers. Self-reports on some variables under study may suffer from self-report bias. Assessment of participants' exposure to psychosocial work stress measures was based on a single evaluation rather than on an individual's cumulative work history.

\section{CONCLUSION}

In conclusion, co-occurrence of overweight/obesity and psychosocial stressors confer greater odds for CVD risk factors than when they occur alone. Intervention at work sites to improve workers' cardiovascular health should move beyond a single risk factor approach to multicomponent therapy that combines psychosocial stress management and overweight-/obesity-related health behaviours, including adoption of a healthy diet and regular exercise regimen.

\section{Funding: No funding sources}

Conflict of interest: None declared

Ethical approval: The study was approved by the Institutional Ethics Committee

\section{REFERENCES}

1. Imeb EO, Anosike MN, Azub DE, Mosaku TO. Work stress among professionals in the building construction industry in Nigeria. Australasian Journal of Construction Economics and Building. 2011;11(3):45-57.

2. Rosengren A, Teo K, Rangarajan S, Kabali C, Khumalo I, Kutty VR, et al. Psychosocial factors and obesity in 17 high, middle-prospective. Urban Rural Epidemiologic Study: Int $\mathrm{J}$ of Obesity. 2015;39:1217-23.

3. Seidler A, Thinschmidt M, Deckert S, Then F, Hegewald J, Nieuwenhuijisen K, et al. The role of psychosocial working condition on burnout and its core component emotional exhaustion-a systemic review. Journal of occupational medicine and toxicology. 2014. DOI: 10.1186/1745-6673-9-10.

4. Fontaine KR, Barofsky I. Obesity and Health related quality of life. Obes Res. 2001;2:(3)173-82.

5. Hannerz H, Albertsen K, Nielsen ML Tuchen F, Burr $\mathrm{H}$. Occupation factors and 5 years weight change among men in a Danish national cohort. Health psycho. 2004;23:283-8.

6. Shield M. long working hours and health. Health Rep. 1999;11:33-48.

7. Niedhammer I, Goldberg M, Leclerc A, David S, Bugel I, Landre M-F. Psychosocial work environment and cardiovascular risk factors in an occupational cohort in France. $\mathrm{J}$ Epidemiol Commun Helath. 1998;52:93-100.

8. Laitinen J, EKE, Sovio U. Stress-related eating and drinking behavior and body mass index and predictors of this behavior. Prev Med. 2001;34:2939.

9. Fontaine KR, Bartlett SJ, Barofsky I. Health-related quality of life among obese persons seeking and not currently seeking treatment. International Journal of Eating Disorders. 2000;27:101-5.

10. Claessen H, Amdt V, Drath $\mathrm{C}$, Brenner $\mathrm{H}$. Overweight, obesity and risk of work disability: a cohort study of construction workers in Germany. Occupational and environmental medicine. 2009;66:(6):9.

11. Rozanski A, Blumenthal JA, Davidson KW, Saab PG, Kubzansky L. The epidemiology, pathphysiology, and management of psychosocial risk factors in cardiac practice: the emerging field of behavioral cardiology. J AM Coll Cardiol. 2005;45(5):637-51.

12. Tsutsumi A, Kayaba K, Yoshimura M, Sawada M, Ishikawa S, Sakai K, et al. Medical School Cohort Study Group: Association between job characteristics and health behavior in Japanese rural workers. International Journal of Behavioral Medicine. 1998;125-42.

13. Lallukka T, Sarlio-Lahteerkorva S, Roos E, Caaksonen M, Rahkonen O, Lahelma E. Working conditions and health among employed women and men: the Helsiniki Health Study. Prev Med. 2004;38:48.

14. Catalina-Romero C, Calvo E, Sânchez-chaparro MA, Valdivielso P, Sainz JC, Cabrera M et al. The relationship between Job stress and Health. 2013;41(2):142-9.

15. Sanghen V, Razzoli M, Carobbio S, Campbell M, Mccallum J, Cero C et al. Psychosocial stress indices hyperphasia and exacerbates diet-induced insulin resistance and the manifestations of the metabolic syndrome. Psycho neuro endocrinology 2013;38:(12);2933-42.

16. Kawakami N, Araki S, Hayashi T, Masumoto T. Relationship between perceived Job-Stress and 
Glyco sylated Hemoglobin in White-collar workers. Industrial Health. 1989:27(4);149-54.

17. Su CT. Association between job strain status and cardiovascular risk in a population of Taiwanese white-collar workers. J. Cire J. 2001;65:509-13.

18. Wardle J, Steptoe A, Oliver G, Lipsey Z. Stress, dietary restraint and food intake. J Psychosom Res. 2000;48:195-202.

19. Thurston RC, Kubzansky LD. Multiple sources of psychosocial disadvantage and risk of coronary heart disease. Psychosomatic Medicine. 2007;69(8):748-55.

20. Ekpenyong CE, Davies K, Antai EE. Cymbopogon citrates stapf (DC) extract ameliorates atherogenic cardiovascular risk in Diabetes-induced dyslipidemia in rats. British Journal of Medicine and Medical Research. 2014;4(28):4695-709.

21. Johnson JV, Hall EM, Therorell T. Combined effect of Job strain and social isolation on cardiovascular disease morbidity and mortality in a random sample of the Swedish male working population. Sc and J Work Environ Health. 1989;15:271-9.

22. Karasek R, Theorell T. Health work stress, productivity and reconstruction of working life. New York, Basic Books, 1990.

23. Chobanian AV, Bakris GL, Black HR, Cushman WC, Green LA, 1220 Jr JL, Jones DW, et al. The seventh report of the national committee on prevention detection, evolution, and treatment of high blood pressure: the JNC 7 report. JAMA. 2003;289:2560-72.

24. Teramoto T, Sasaki J, Ueshima H, Egusa G, Kinoshita M, Shimamoto K, et al. Diagnostic criteria for Dyslipidemia. Journal of Atherosclerosis and Thrombosis. 2007;14(4):155-8.

25. Ghost A, Ghost T. Modification of Kuppuswamy's socio-economic status scale in context to Nepal. Indian J. Pediatr. 2009;46:1104-5.

26. Ekpenyong CE, Etukumana EA. Ethnicity, family socio-economic inequalities, and prevalence of vaginal Douching among college students. The implication for health. Journal of American College Health. 2013;61(4):222-30.

27. Heraclides AM, Chandola T, Witte DR, Brunner EJ. Work Stress, Obesity and the Risk of Type 2 diabetes: gender-specific bidirectional effect in the Whitehall 11 study. Epidemiology. 2012;20(2):42833.

28. Thurstone RC, Kubzansky LD. Multiple sources of psychosocial disadvantage and risk of coronary heart disease. Psychosomatic Medicine. 2007;69:748-55.

29. Karasek R. Brisson C, Kawakami N, Houtman I, Bongers $\mathrm{P}$, Amick B. The job content questionnaire (JCQ): an instrument for internationally comparative assessment of psychosocial job characteristics. J Occup Health Psychol. 1998:3(4):322-55.
30. Rozanski A, Blumenthal JA, Kaplan J. Impact of psychosocial factors on the pathogenesis of cardiovascular disease and implications for therapy. Circulation. 1999;99(16):2192-217.

31. Heraclides A, Chandola T, Witte DR, Brunner EJ. Psychosocial stress at work doubles the risk of type 2 diabetes in middle-aged women. Diabetes care. 2009;32(12);2230-5.

32. Ostry AS, Radi S, Louie AM, LaMontagne AD. Psychosocial and other working conditions in relation to body mass index in a representative sample of Australian workers. BMC Public Health 2006;6:53. dio.10.1186/1471-2458-6-53.

33. Smith PM, Glazier RH, Lu H, Mustard CA. The psychosocial work environment and incident diabetes in Ontario Canada. Occupational Medicine. 2012;2(62):413-9.

34. Heraclides A, Chandola T, Witte DR, Brunner EJ. Psychosocial stress at work doubles the risk of type 2 diabetes in middle-aged women: Evidence from the Whitehall II study. Diabetes Care. 2009;32(12): 2230-5.

35. Murphy NF, Maclntyre K, Stewart S, Hart CL, Hole D, McMurray JJV. Long term cardiovascular consequence of obesity 20 years follow-up of more than 1500 middle-aged men and women (the Renfrew-Paisly study). Eur Heart J. 2006;27(1):96106.

36. Gelber RP, Kurth T, Manson JF, Gaziano JM. Body mass index and mortality in man: evaluating the shape of the association. Int $\mathbf{J}$ Obes. 2007;31(8):1240-7.

37. Kouvonen A, Kivimäki M, Virtanen M, Pentti J, Vahtera J. Work stress, smoking status and smoking intensity: an observational study of 46190 employees. J Epidemiol community Health. 2005;59:63-9.

38. Kouvonen A, Kivimaki M, COX SJ, Cox T, Vahtera J. Relationship between work stress and body mass index among 45, 810 female and male employees. Psychosom Med. 2005;67:577-83.

39. Head J, Stanfeld SA, Siegrist J. The psychosocial work environment and alcohol dependence: a prospective study. Occup. Environ Med. 2004;61:219-44.

40. Kouvonen A, Kivimäki M, Virtanen M, Heponiemi T, Elovaino M, Pentti J, et al. Effort-reward imbalance at work and the co-occurrence of lifestyle risk factors: cross-sectional survey in a sample of 36,127 public sector employees MBC public health 2006;6:24. dio:10.1186/1471-2458-6-24.

Cite this article as: Ekpenyong CE, Davies K. Effect of co-occurrence of overweight/obesity and psychosocial stress dimensions on risk factors for cardiovascular disease among construction workers. Int J Community Med Public Health 2016;3:1795-802. 